Article

\title{
Energy Performance Investigation of a Direct Expansion Ventilation Cooling System with a Heat Wheel
}

\author{
Miklos Kassai ${ }^{(D)}$ \\ Department of Building Service Engineering and Process Engineering, Faculty of Mechanical Engineering, \\ Budapest University of Technology and Economics, Muegyetem rkp. 3., H-1111 Budapest, Hungary; \\ kassai@epgep.bme.hu; Tel.: +36-20-362-8452
}

Received: 11 October 2019; Accepted: 7 November 2019; Published: 8 November 2019 updates

\begin{abstract}
Climate change is continuously bringing hotter summers and because of this fact, the use of air-conditioning systems is also extending in European countries. To reduce the energy demand and consumption of these systems, it is particularly significant to identify further technical solutions for direct cooling. In this research work, a field study is carried out on the cooling energy performance of an existing, operating ventilation system placed on the flat roof of a shopping center, located in the city of Eger in Hungary. The running system supplies cooled air to the back office and storage area of a shop and includes an air-to-air rotary heat wheel, a mixing box element, and a direct expansion cooling coil connected to a variable refrigerant volume outdoor unit. The objective of the study was to investigate the thermal behavior of each component separately, in order to make clear scientific conclusions from the point of view of energy consumption. Moreover, the carbon dioxide cross-contamination in the heat wheel was also analyzed, which is the major drawback of this type heat recovery unit. To achieve this, an electricity energy meter was installed in the outdoor unit and temperature, humidity, air velocity, and carbon dioxide sensors were placed in the inlet and outlet section of each element that has an effect on the cooling process. To provide continuous data recording and remote monitoring of air handling parameters and energy consumption of the system, a network monitor interface was developed by building management system-based software. The energy impact of the heat wheel resulted in a $624 \mathrm{kWh}$ energy saving and $25.1 \%$ energy saving rate for the electric energy consumption of the outdoor unit during the whole cooling period, compared to the system without heat wheel operation. The scale of $\mathrm{CO}_{2}$ cross-contamination in the heat wheel was evaluated as an average value of $16.4 \%$, considering the whole cooling season.
\end{abstract}

Keywords: building energy efficiency; heat wheel; direct expansion cooling; ventilation system; energy consumption

\section{Introduction}

The use of environmental control systems has significantly increased in the building sector in order to reduce the energy consumption of heating, ventilation, and air-conditioning (HVAC) systems [1]. Air handling units (AHUs) are one of the most complex building service systems [2], and can include heating, cooling, humidifier, mixing element, and heat recovery units, in order to provide the required indoor air quality and thermal comfort in conditioned spaces [3].

In a typical AHU, chilled water in the cooling coils cools the air, and hot water (or steam) in the heating coils heats the air, in order to maintain the desired temperature of the supply [4]. The supply and return fans assist in moving the air for heat exchange, as well as circulating it in the HVAC system at the required flow rate [5]. Several components are part of a typical system, i.e., the chiller, the boiler, the supply and return fans, and the water pump that consumes a lot of energy [6]. 
Direct expansion ventilation units are becoming more commonly used central air-conditioning technical solutions, in which a refrigerant is directly delivered to the cooling (and heating) coil [7]. These systems have the potential to save cooling and heating energy use, since they do not require any water pumps for their operation, compared to water-based central air conditioning systems [8,9].

Developers are working really hard to minimalize the energy consumption of their developed devices; however, there are many imperfections in the actual available product catalogues, technical data, and technical support service systems, especially for the annual energy designing provided by the ventilation producers for building service and energy design engineers [10,11]. Therefore, it would be particularly significant to have measured and recorded data obtained from field studies [12,13], which may be utilized in the course of design work, and which would allow a proper estimation of the expected realizable annual energy consumption of air handling elements in the function of the temperature and relative humidity of ambient and indoor air and operating parameters [14].

Stamatescu et. al [15] presented the implementation and evaluation of a data mining methodology based on collected data from a more than one-year operation. The case study was carried out on four AHUs of a modern campus building for preliminary decision support for facility managers. The results are useful for deriving the behavior of each piece of equipment in various mode of operation and can be built upon for fault detection or energy efficiency applications. The imperfection of their work is the missing data for air condition parameters (temperature and humidity) between the coils and mixing box; before and after the fans, which cannot be neglected, since the electrical motor of the fans increases the air temperature and decreases the relative humidity; and the air volume flow rate, which changes during the operation. All these missing parameters have a significant effect on the energy efficiency of the ventilation system.

Hong et. al [16] conducted a case study on a running AHU for data-driven predictive model development. In order to develop the optimal model, input variables, the number of neurons and hidden layers, and the period of the training data set were considered. The results and conclusions presented for the one-year field study could have much better reflected the reality from the view point of energy performance, if further temperature and relative humidity sensors had been placed between the coils and humidifier element, before and after the fans. Only focusing on energy performance data recording is not enough, since the desired indoor air quality and thermal comfort are also significant parameters that need to be considered. To draw a more exact conclusion from this point of view, the $\mathrm{CO}_{2}$ parameter should also have been monitored and recorded in the outdoor air inlet (OA) and supply air outlet (SA) sections in the investigated AHU.

Based on a literature review of the field, there are some case studies in which the heat recovery unit has also been considered in the ventilation system. Noussan et. al [17] presented results obtained from an operation data analysis of an AHU serving a large university classroom. The main drivers of energy consumption are highlighted, and the classroom occupancy is found to have a significant importance in the energy balance of the system. The availability of historical operation data allowed a comparison of the actual operation of the AHU and the expected performance from nominal parameters to be performed. Calculations were made considering the operation analysis of the heat recovery unit over different years; however, the existing system does not include any heat or energy recovery devices, so there are no exact measured data from this point of view.

Bareschino et. al [18] compared three alternative hygroscopic materials for desiccant wheels considering the operation of the air handling unit they are installed in. Their results demonstrated that a primary energy saving of about $20 \%, 29 \%$, and $15 \%$ can be reached with silica-gel, milgo, and zeolite-rich tuff desiccant wheel-based air handling units, respectively. The results were given based on a simulation and there is no exact measured data, which would be significant for making precise and clear energetic conclusions.

In this work, a field study is carried out on an existing, operating ventilation system that includes an air-to-air rotary heat wheel, a mixing box element, and a direct expansion cooling coil connected to a variable refrigerant volume outdoor unit. One of the main objectives of the present 
paper is to investigate the cooling energy performance and thermal behavior of each air handling component separately. To achieve this, an advanced data recording and remote monitoring system was considerately developed by building management system-based software. The system includes an electricity energy meter installed in the outdoor unit, as well as temperature, humidity, air velocity, and $\mathrm{CO}_{2}$ sensors placed in the inlet and outlet section of all the air handling elements that have an effect on the cooling process. The purpose of the $\mathrm{CO}_{2}$ measurements was to investigate the $\mathrm{CO}_{2}$ cross-contamination, which occurs from the exhaust air flow to the supply air flow in the air-to-air rotary heat wheel, resulting in indoor air quality degradation. The novelty of this research is the accurate determination of the seasonal effectiveness and the energy saving impact of the heat wheel on the electric energy consumption of the outdoor unit. Moreover, the relative average and maximum value of $\mathrm{CO}_{2}$ cross-contamination in the rotary heat recovery using the developed measurement system in the cooling period are presented. A further innovation in this study is the analytical evaluation method developed, which shows a good agreement between the calculated and measured energy consumption.

\section{Materials and Methods}

The selected air handling unit (AHU) is located on the flat roof of a shopping center, located in the city of Eger in Hungary, which has supplied fresh air to the back-office and storage area of a shop since 2017.

\subsection{Description of the Investigated Central Ventilation System}

The main air handling components of the system are an air-to-air rotary heat wheel, a mixing box element, and direct expansion cooling/heating (DX) coil connected to a variable refrigerant volume outdoor unit. Figure 1 shows the elements of the investigated AHU.

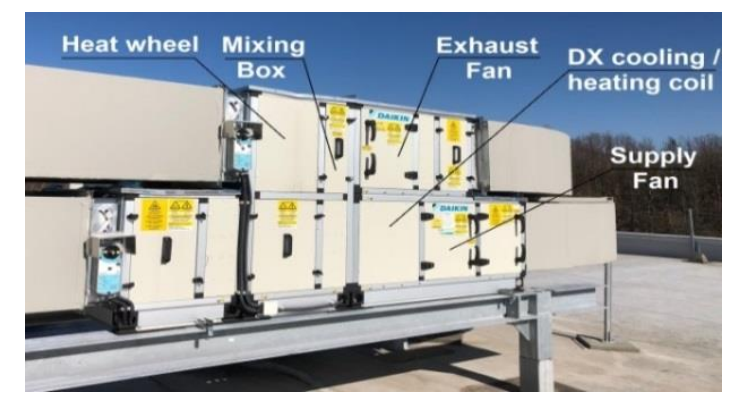

Figure 1. Photo from the investigated air handling units (AHU).

The specification of the AHU can be seen in Table 1.

Table 1. Specification of the investigated AHU [19].

\begin{tabular}{ccc}
\hline Parameter & Value & Unit \\
\hline Width $\times$ Height $\times$ Length & $1450 \times 1340 \times 2897$ & $\mathrm{~mm}$ \\
Air flow & 1060 & $\mathrm{~m}^{3} / \mathrm{h}$ \\
External Pressure Drop & 280 & $\mathrm{~Pa}$ \\
Weight & 595 & $\mathrm{~kg}$ \\
\hline
\end{tabular}

Figure 2 shows the outdoor unit which is connected with refrigerant pipes to the DX coil and is located in the AHU. 


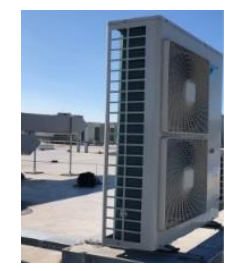

Figure 2. Photo from the outdoor unit.

Technical data of the unit can be seen in Table 2.

Table 2. Technical data of the outdoor unit [19].

\begin{tabular}{ccc}
\hline Parameter & Value & Unit \\
\hline Total Cooling Capacity & 10.9 & $\mathrm{~kW}$ \\
Refrigerant & R410a & - \\
EER & 3.99 & - \\
Fin Material & Aluminium & - \\
Tube Material & Copper & - \\
\hline
\end{tabular}

Table 3 shows the specification of the air-to-air recovery heat wheel in the cooling period.

Table 3. Specification of the investigated heat wheel [19].

\begin{tabular}{ccc}
\hline Parameter & Value & Unit \\
\hline Heat recovered & 2 & $\mathrm{~kW}$ \\
Effectiveness & 74.9 & $\%$ \\
Diameter & 600 & $\mathrm{~mm}$ \\
\hline
\end{tabular}

\subsection{Description of the Developed Measurement System}

In total, six temperature and relative humidity sensors, three $\mathrm{CO}_{2}$ sensors and three air velocity sensors were placed in the inlet and outlet section of each air handling element and an electricity energy meter was installed in the outdoor unit. The placement of the measurement points can be seen in Figure 3. The technical data of the installed sensors and instrument can be read in Table 4.

a)

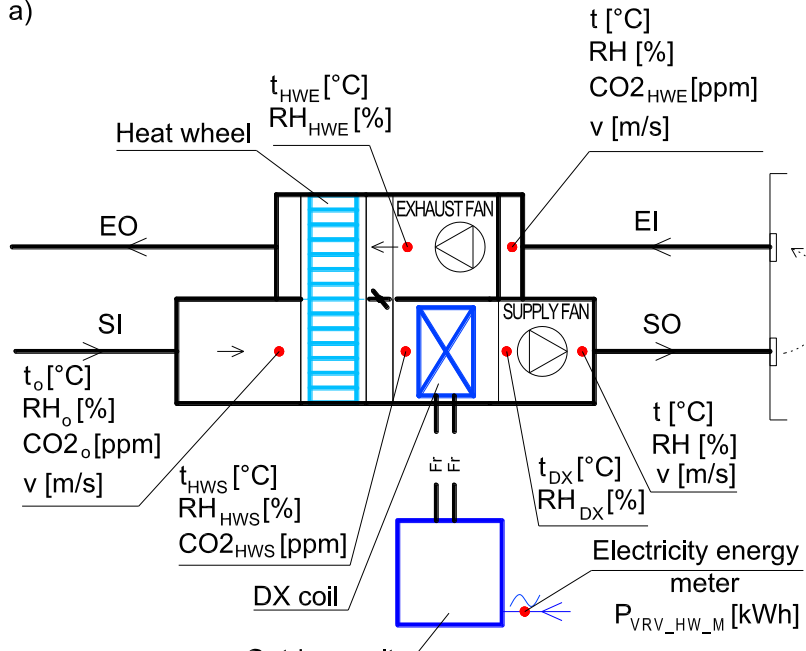

Outdoor unit

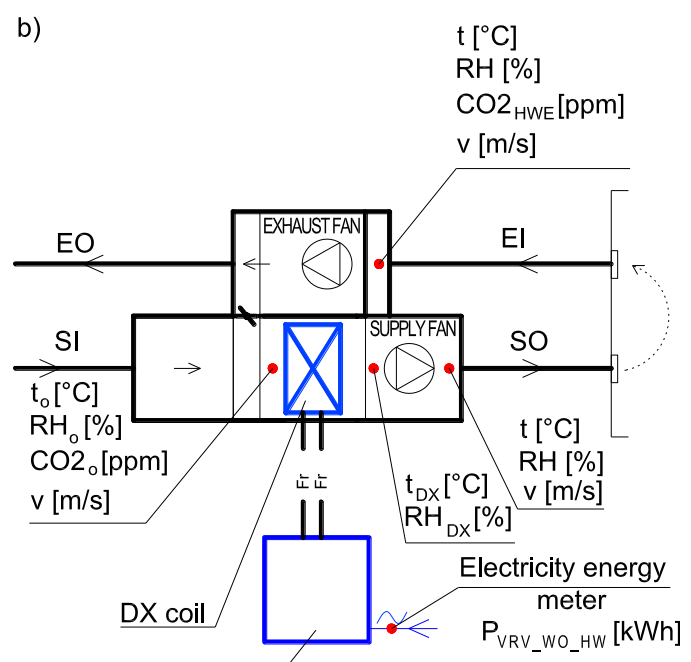

Outdoor unit

Figure 3. Schematic diagram (a) for the placement of the measurement points on the real operating $\mathrm{AHU}$ and (b) the AHU without a heat recovery operation assumption. 
Table 4. Specification of the sensors and instrument.

\begin{tabular}{llcc}
\hline Model & Device & Working Range & Accuracy \\
\hline Honeywell VF20-3B65NW & Temperature sensor & $-40-150{ }^{\circ} \mathrm{C}$ & $\pm 0.4{ }^{\circ} \mathrm{C}$ \\
Honeywell LFH20-2B65 & Humidity sensor & $10-90 \%$ & $\pm 3 \%$ \\
Honeywell AQS-KAM-20 & $\mathrm{CO}_{2}$ sensor & $0-2000 \mathrm{ppm}$ & $\pm 50 \mathrm{ppm}$ \\
Honeywell AV-D-10 & Air velocity sensor & $2-20 \mathrm{~m} / \mathrm{s}$ & $\pm 0.2 \mathrm{~m} / \mathrm{s}$ \\
Inepro Metering Pro 380 & Electricity energy meter & $5-100 \mathrm{~A}$ & $\pm 1 \%$ \\
\hline
\end{tabular}

The recording of the measured data took place in an hourly period. With regards to the measurement accuracy, temperature sensors are normally used with a $\pm 0.4{ }^{\circ} \mathrm{C}$ accuracy, humidity sensors with a $\pm 3 \%$ accuracy, an air velocity sensor with a $\pm 0.2 \mathrm{~m} / \mathrm{s}$ accuracy, carbon dioxide sensors with a \pm 50 ppm accuracy, and an electric energy meter with a $1 \%$ of full scale accuracy. Among the monitoring air handling data, the air temperature and relative humidity data of the inlet and outlet sections of the DX cooling coil, energy recovery unit, and outdoor were used to investigate the energy performance and thermal behaviour of these air handling elements in the AHU in the cooling season.

The specification of the sensors and electricity energy meter used for monitoring of the investigated AHU can be seen in Table 4 .

For the monitoring and recording of the various air condition parameters and the electrical energy consumption of the outdoor unit, the CentraLine Building Management System (BMS) software (version 2019) solution from Honeywell was implemented on a central server. Figure 4 shows a picture of the target building, along with a representative BMS screen for the investigated air handling unit.

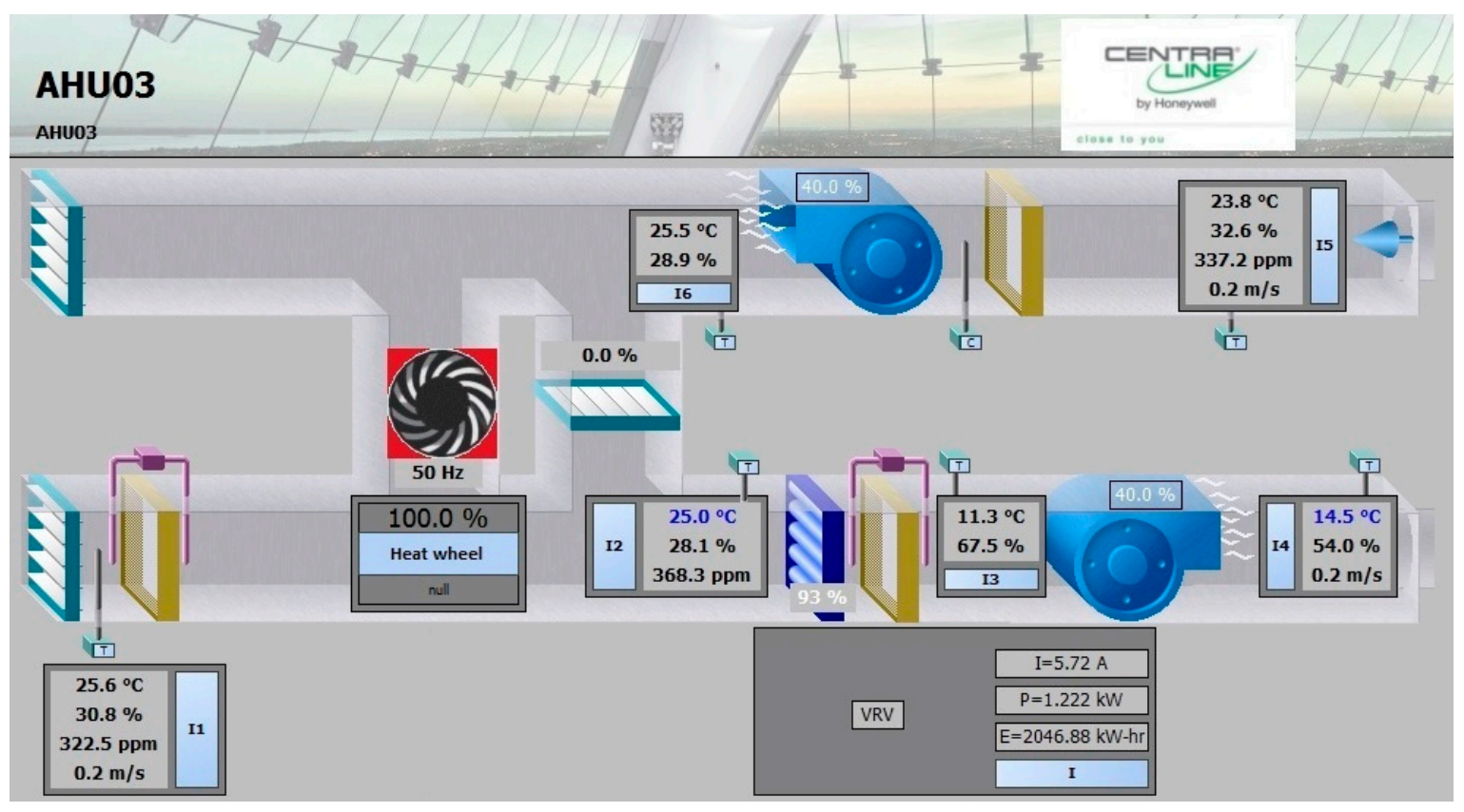

Figure 4. A screenshot of the investigated AHU in the Building Management System (BMS).

Access to the BMS software was remotely enabled. Within this technical context, the necessary data were collected for this field study. Data were collected online at hourly intervals, saved, and stored on a computer from a distance.

\section{Evaluation of the Data Recorded}

To investigate the energy performance of the AHU, using the measurements, the following mathematical approaches were implemented. 


\subsection{Calculation Formulas for Measured Data Evaluation}

Using the measured air temperature and relative humidity data, the specific humidity could be calculated to obtain the enthalpy of the air. To achieve this, the water vapor saturation pressure $\left(P_{w s}\right)$ was first calculated with Equation (1) [20]:

$$
P_{w s}=A \cdot 10^{\left(\frac{m t}{t+t_{n}}\right)} \cdot 100,
$$

where $P_{w s}$ is the saturation pressure of the water vapor in $\mathrm{Pa} ; \mathrm{t}$ is the air temperature in ${ }^{\circ} \mathrm{C}$; and $\mathrm{A}, \mathrm{m}$, and $t_{n}$ are constant values in -. Since the temperature range during the measurements was between -20 and $+50{ }^{\circ} \mathrm{C}$, the constant values (in $0.083 \%$ maximum error) were as follows: $A=6.116441$; $m=7.591386 ; t_{n}=240.7263$ [20]. The constant value of 100 in Equation (1) represents the conversion of the saturation pressure of water vapor from $\mathrm{hPa}$ to $\mathrm{Pa}$.

To obtain the moisture content, the partial pressure of water vapor in the air at a given relative humidity was also calculated with Equation (2) [20]:

$$
P_{w}=P_{w s} \cdot \frac{R H}{100},
$$

where $P_{w}$ is the partial pressure of water vapor in $\mathrm{Pa}$ and $\mathrm{RH}$ is the relative humidity of the air in \%. The constant value of 100 in Equation (2) represents the conversion of relative humidity from \% to -.

The moisture content was calculated with Equation (3) [21]:

$$
x=0.622 \cdot \frac{P_{w}}{P_{o}-P_{w}}
$$

where $x$ is the moisture content of the air in $\mathrm{kg} / \mathrm{kg}, P_{o}$ is the barometric pressure in $\mathrm{Pa}$, and the 0.622 constant value is the molecular weight ratio of water vapor to dry air.

The enthalpy was calculated with Equation (4) [21]:

$$
h=c_{p a} \cdot t+x \cdot\left(c_{p w} \cdot t+2500\right),
$$

where $h$ is the enthalpy of the air in $\mathrm{kJ} / \mathrm{kg}, c_{p a}$ is the specific heat of air at constant pressure in $\mathrm{kJ} /\left(\mathrm{kg} \cdot{ }^{\circ} \mathrm{C}\right)$, $c_{p w}$ is the specific heat of water vapor at constant pressure in $\mathrm{kJ} /\left(\mathrm{kg} \cdot{ }^{\circ} \mathrm{C}\right)$, and the constant value of 2500 represents the evaporation heat in $\mathrm{kJ} /\left(\mathrm{kg} \cdot{ }^{\circ} \mathrm{C}\right)$.

\subsection{Formulas for Energy Calculations}

Considering the fact that there is balanced ventilation, the effectiveness values of the heat wheel were determined from the air temperature measured values using Equation (5) [22,23]:

$$
\varepsilon_{S}=\frac{\left(t_{H W S}-t_{o}\right)}{\left(t_{H W E}-t_{o}\right)},
$$

where $\varepsilon_{S}$ is the real sensible effectiveness of the heat wheel given by the measured data in -, $t_{H W S}$ is the air temperature in the supply outlet section of the heat wheel in ${ }^{\circ} \mathrm{C}, t_{H W E}$ is the air temperature in the exhaust inlet section of the heat wheel in ${ }^{\circ} \mathrm{C}$, and $t_{o}$ is the ambient air temperature which is equal to the air temperature in the supply inlet section of the heat wheel in ${ }^{\circ} \mathrm{C}$.

To get information about the seasonal energy performance of the heat recovery during the cooling period, the average of the sensible effectiveness was calculated with Equation (6):

$$
\bar{\varepsilon}_{s_{-} A V}=\frac{\sum_{i=1}^{n} \varepsilon_{S_{-} i}}{n},
$$


where $\bar{\varepsilon}_{s_{-} A V}$ is the average of the sensible effectiveness of the heat wheel given by the measured data in the cooling season in - and $\mathrm{n}$ is the number of measurements.

The maximum value of the sensible effectiveness was also analyzed during the whole cooling season, which was calculated with Equation (7):

$$
\varepsilon_{S_{-} M A X}=\operatorname{MAX}\left(\varepsilon_{s_{-} i} \ldots \varepsilon_{S_{-} n}\right),
$$

where $\bar{\varepsilon}_{S_{-} M A X}$ is the maximum value of the sensible effectiveness of the heat wheel given by the measured data in the cooling season in -.

To calculate the energy saving of the heat wheel in the cooling season, Equation (8) was used:

$$
Q_{H W_{-} \text {saved }}=\dot{m}_{S} \cdot\left(h_{0}-h_{H W S}\right) \cdot \tau \text {, }
$$

where $Q_{H W_{-} \text {saved }}$ is the energy saving of the heat wheel in $\mathrm{kWh} ; \dot{m}_{S}$ is the air mass flow rate delivered by the fans in $\mathrm{kg} / \mathrm{s}$, which is calculated by the multiplication of the measured air velocity in $\mathrm{m} / \mathrm{s}$ and the internal cross-section of air duct in $0.7398 \mathrm{~m}^{2}$ and approached a $1.2 \mathrm{~kg} / \mathrm{m}^{3}$ constant air density; $h_{\mathrm{o}}$ is the ambient air enthalpy which is equal to the air enthalpy in the supply inlet section of the heat wheel in $\mathrm{kJ} / \mathrm{kg}$; $h_{H W S}$ is the air enthalpy in the supply outlet section of the heat wheel in $\mathrm{kJ} / \mathrm{kg}$; and $\tau$ is the time in hours. The average air volume flow rate was evaluated as $1060 \mathrm{~m}^{3} / \mathrm{h}$ during the cooling season.

To calculate the cooling energy consumption of the DX coil, Equation (9) was used:

$$
Q_{D X \_H W}=\dot{m}_{s} \cdot\left(h_{H W S}-h_{D X}\right) \cdot \tau,
$$

where $Q_{D X \_H W}$ is the cooling energy consumption of the DX coil in $\mathrm{kWh}$, and $\mathrm{h}_{\mathrm{DX}}$ is the air enthalpy in the supply outlet section of the DX coil in $\mathrm{kJ} / \mathrm{kg}$, which is equal to the supply air condition.

In order to investigate more the energy saving impact of the heat wheel on the DX coil, the cooling energy consumption of DX coil was also determined by Equation (10), neglecting the air-to-air rotary heat wheel operation, when the DX coil directly cools the hot ambient air to the supply air conditions.

$$
Q_{D X \_W O \_H W}=\dot{m}_{s} \cdot\left(h_{O}-h_{D X}\right) \cdot \tau,
$$

where $Q_{D X \_W O}{ }_{-} H W$ is the cooling energy consumption of the DX coil without the heat wheel operation in $\mathrm{kWh}$.

The calculated electric energy consumption of the outdoor unit was calculated with Equation (11):

$$
P_{V R V \_H W}=\frac{Q_{D X_{-} H W}}{E E R},
$$

where $P_{V R V_{-} H W}$ is the calculated electric energy consumption of the outdoor unit with the heat wheel operation in $\mathrm{kWh}$, and EER is the energy efficiency ratio, given by the producer in -.

Moreover, the real electric energy consumption of the outdoor unit $\left(P_{V R V \_H W_{-} M}\right)$ was also measured during the cooling season, in order to see the agreement between values of the measured data and calculations using the recorded air condition parameters $\left(P_{V R V_{-} H W}\right)$. The difference between the measured and calculated electric energy consumption was determined with Equation (12):

$$
\Delta P_{V R V_{-} H W}=P_{V R V_{-} H W_{-} M}-P_{V R V_{-} H W},
$$

where $\Delta P_{V R V_{-} H W}$ is the difference between the measured and calculated electric energy consumption of the outdoor unit with the heat wheel operation in $\mathrm{kWh}$. 
The rate of deviation of the measured and calculated electric energy consumption of the outdoor unit related to the measured data was calculated with Equation (13):

$$
\Delta P_{V R V \_H W_{-} R E L}=\frac{\Delta P_{V R V \_H W}}{P_{V R V \_H W}} \cdot 100,
$$

where $\triangle P_{V R V_{-} H W_{-} R E L}$ is the rate of deviation of the measured and calculated electric energy consumption of the outdoor unit in \%.

The electric energy consumption of the outdoor unit without the heat wheel operation was calculated with Equation (14):

$$
P_{V R V_{-} W O_{-} H W}=\frac{Q_{D X_{-} W O_{-} H W}}{E E R},
$$

where $P_{V R V_{-} W O_{-} H W}$ is the electrical energy consumption of the outdoor unit without the heat wheel operation in $\mathrm{kWh}$ when it directly cools the hot ambient air to the supply air conditions via the DX coil during the cooling season.

The energy saving of the heat wheel in terms of the electric energy consumption of the outdoor unit was calculated with Equation (15):

$$
\Delta P_{V R V \_H W_{-} \text {saved }}=P_{V R V_{-} W_{-} H W}-P_{V R V_{-} H W},
$$

where $\Delta P_{V R V_{-} H W_{-} \text {saved }}$ is the amount of energy saved by the heat wheel in terms of the calculated electric energy consumption of the outdoor unit compared to that without the heat recovery operation in $\mathrm{kWh}$.

The energy saving impact of the heat wheel on the electric energy consumption of the outdoor unit, compared to the system without the heat wheel operation, was calculated with Equation (16):

$$
\Delta P_{V R V \_H W_{\_} \text {saved_REL }}=\frac{\Delta P_{V R V \_H W \_s a v e d}}{P_{V R V \_W O \_H W}} \cdot 100,
$$

where $\Delta P_{V R V \_H W_{-} \text {saved_REL }}$ is the energy saving rate of the heat wheel for the electric energy consumption of the outdoor unit, compared to the system without heat the wheel operation, in \%.

The value of the actual energy efficiency ratio of the outdoor unit given obtained the field study was determined with Equation (17) for the investigated cooling season to compare the data provided by the producer:

$$
E E R_{M}=\frac{Q_{D X \_H W}}{P_{V R V \_H W_{-} M}} \cdot 100,
$$

where $E E R_{M}$ is the evaluated energy efficiency ratio (-) based on the measurement during the whole investigated cooling season.

\subsection{Formulas for Carbon Dioxode Cross-Contamination in the Heat Wheel}

The scale of carbon dioxide $\left(\mathrm{CO}_{2}\right)$ cross-contamination in the air-to-air rotary heat recovery wheel was also investigated by measurements in the heat wheel during the operation of the air handling unit in the cooling period. To achieve this, the $\mathrm{CO}_{2}$ concentration difference between the supply inlet and outlet sections of the heat wheel was first determined with Equation (18):

$$
\Delta C_{\mathrm{CO} 2_{2} \text { cross }}=\mathrm{C}_{\mathrm{CO} 2 \_\mathrm{HWS}}-\mathrm{C}_{\mathrm{CO} 2 \_\mathrm{o}}
$$

where $\Delta C_{C O 2}$ cross is the scale of the $\mathrm{CO}_{2}$ cross-contamination in the heat wheel in a given hour in ppm; $\mathrm{C}_{\mathrm{CO} 2 \_\mathrm{HWS}}$ is the $\mathrm{CO}_{2}$ concentration in the supply outlet section of the heat wheel in ppm; and $C_{\mathrm{CO}_{-} \mathrm{o}}$ is the $\mathrm{CO}_{2}$ concentration of the ambient air in ppm, which is equal to the $\mathrm{CO}_{2}$ concentration in the supply inlet section of the heat wheel in ppm. 
Having completed the measurements, the average of the $\mathrm{CO}_{2}$ cross-contamination values was taken, and the ratio of the result and the supplied average $\mathrm{CO}_{2}$ concentration was calculated by Equation (19):

$$
\overline{\Delta C}_{\text {CO2_cross_AV }}=\frac{\sum_{i=1}^{n} \Delta C_{\text {CO2_cross_ } i}}{n},
$$

where $\Delta C_{C O 2}$ cross_ $A V$ is the average of the $\mathrm{CO}_{2}$ cross-contamination values in ppm and $n$ is the number of measurements.

Since $\mathrm{CO}_{2}$ cross-contamination occurs from the exhaust section to the supply section in the heat wheel, the average of the measured $\mathrm{CO}_{2}$ values in the exhaust inlet section of the heat wheel was also calculated with Equation (20) using the data measured:

$$
\overline{\mathrm{C}}_{\mathrm{CO}{ }_{-} H W \mathrm{H}_{-} A V}=\frac{\sum_{i=1}^{n} \mathrm{C}_{\mathrm{CO}_{\_} H W H_{-} i}}{n},
$$

where $C_{C O 2}{ }_{H W E} A V$ is the average value of the $\mathrm{CO}_{2}$ concentration in the exhaust inlet section of the heat wheel in ppm and $n$ is the number of measurements.

Equation (21) was used to obtain the relative average of differences:

$$
\overline{\Delta C}_{C O 2 \_R E L}=\frac{\overline{\Delta C}_{C O 2 \_c r o s s \_A V}}{\bar{C}_{C O 2 \_H W E \_A V}} \cdot 100,
$$

where $\Delta C_{C O 2}$ REL is the relative average of $\mathrm{CO}_{2}$ cross-contamination in $\%$, considering the $\mathrm{CO}_{2}$ concentration content in the exhaust inlet section of the heat wheel in ppm.

The maximum value of $\mathrm{CO}_{2}$ cross-contamination was also analyzed during the whole cooling season, which was calculated with Equation (22):

$$
C_{C O 2 \_R E L \_M A X}=\left[\operatorname{MAX}\left(\frac{C_{C O 2 \_c r o s s \_} i}{C_{C O 2 \_H W E \_}} \cdots \frac{C_{C O 2 \_c r o s s \_n}}{C_{C O 2 \_H W E \_n}}\right)\right] \cdot 100,
$$

where $C_{C O 2 \_R E L \_M A X}$ is the maximum value of $\mathrm{CO}_{2}$ cross-contamination in the heat wheel in the cooling season given by the measured data in $\%$.

\section{Results and Discussion}

The reference period of the study is the year 2019, more specifically, the cooling period from June 1st to August 31st for a total of 92 days and 25,296 data samples for each of the used measurement points. The AHU is intermittently operated $12 \mathrm{~h}$ /day from 8:00 till 20:00 7 days/week. Since this research work focused on the ventilation energy saving of the heat recovery unit's DX cooling coil, the mixing box was shut off during the data recording.

The air handling parameters obtained from the field study for the investigated AHU are illustrated in Figures 5-7 with a monthly timescale. Since the ambient air temperature was the highest in June during the whole cooling season, this relevant month was selected to present the measured data resulting from the data collection.

Figure 5 shows the temperature of the outdoor air $\left(t_{0}\right)$, the air in the supply outlet sections of the heat wheel ( $\left.t_{\mathrm{HWS}}\right)$ and DX coil ( $\left.\mathrm{t}_{\mathrm{DX}}\right)$, and the exhaust inlet section of the heat wheel $\left(\mathrm{t}_{\mathrm{HWE}}\right)$ over time at hourly intervals in June.

Considering the hottest periods in the cooling season, the ambient air temperature decreased by about $4-5{ }^{\circ} \mathrm{C}$ due to the pre-cooling effect of the heat wheel, and by an additional $18-20{ }^{\circ} \mathrm{C}$, provided by air cooling of the DX coil.

Figure 6 shows the measured relative humidity of the outdoor air $\left(\mathrm{RH}_{\mathrm{o}}\right)$, the air in the supply outlet sections of the heat wheel $\left(\mathrm{RH}_{\mathrm{HWS}}\right)$ and $\mathrm{DX}$ coil $\left(\mathrm{RH}_{\mathrm{DX}}\right)$, and the exhaust inlet section of the heat wheel $\left(\mathrm{RH}_{\mathrm{HWE}}\right)$ over time at hourly intervals in June. 


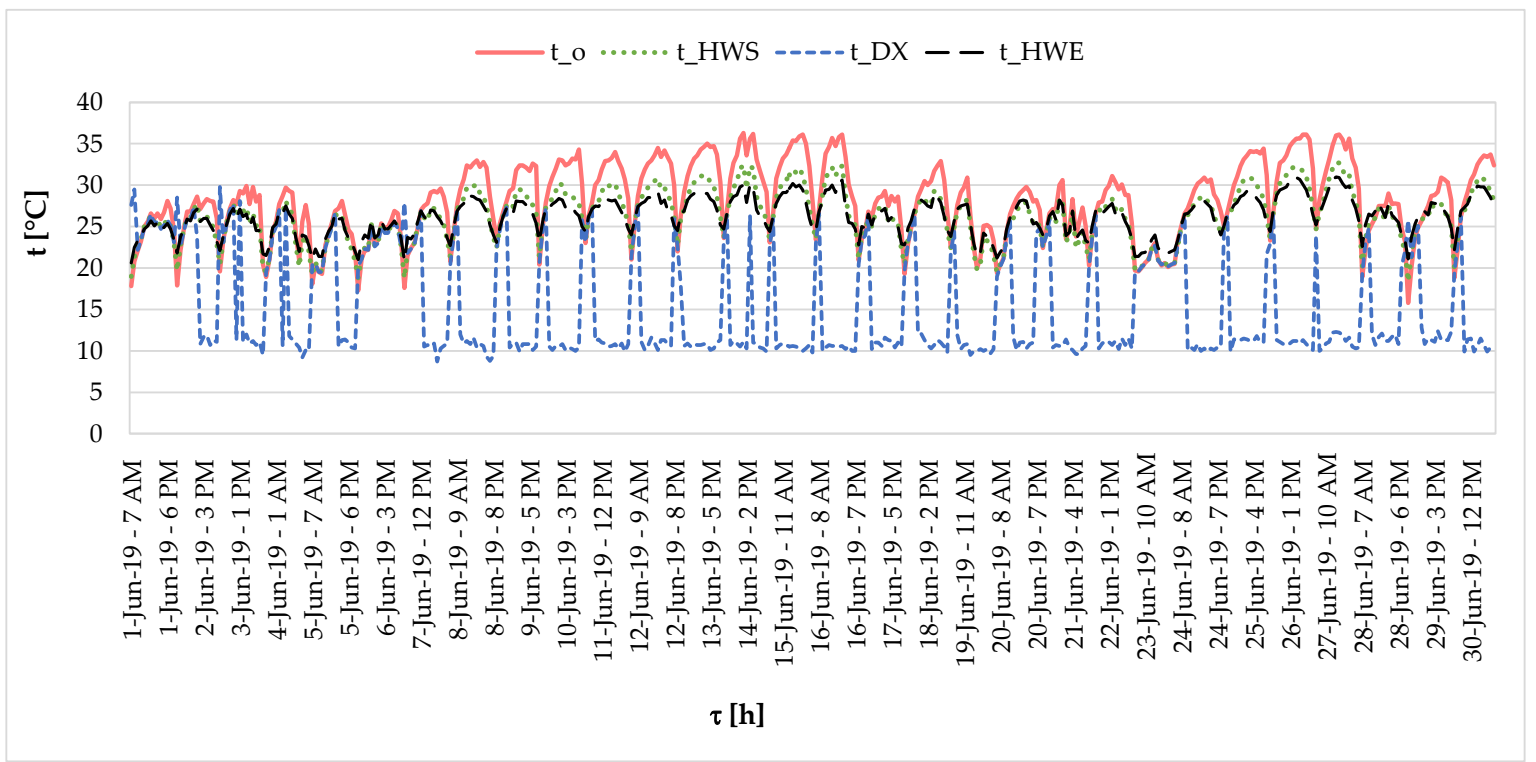

Figure 5. The air temperature values in the air handling processes.

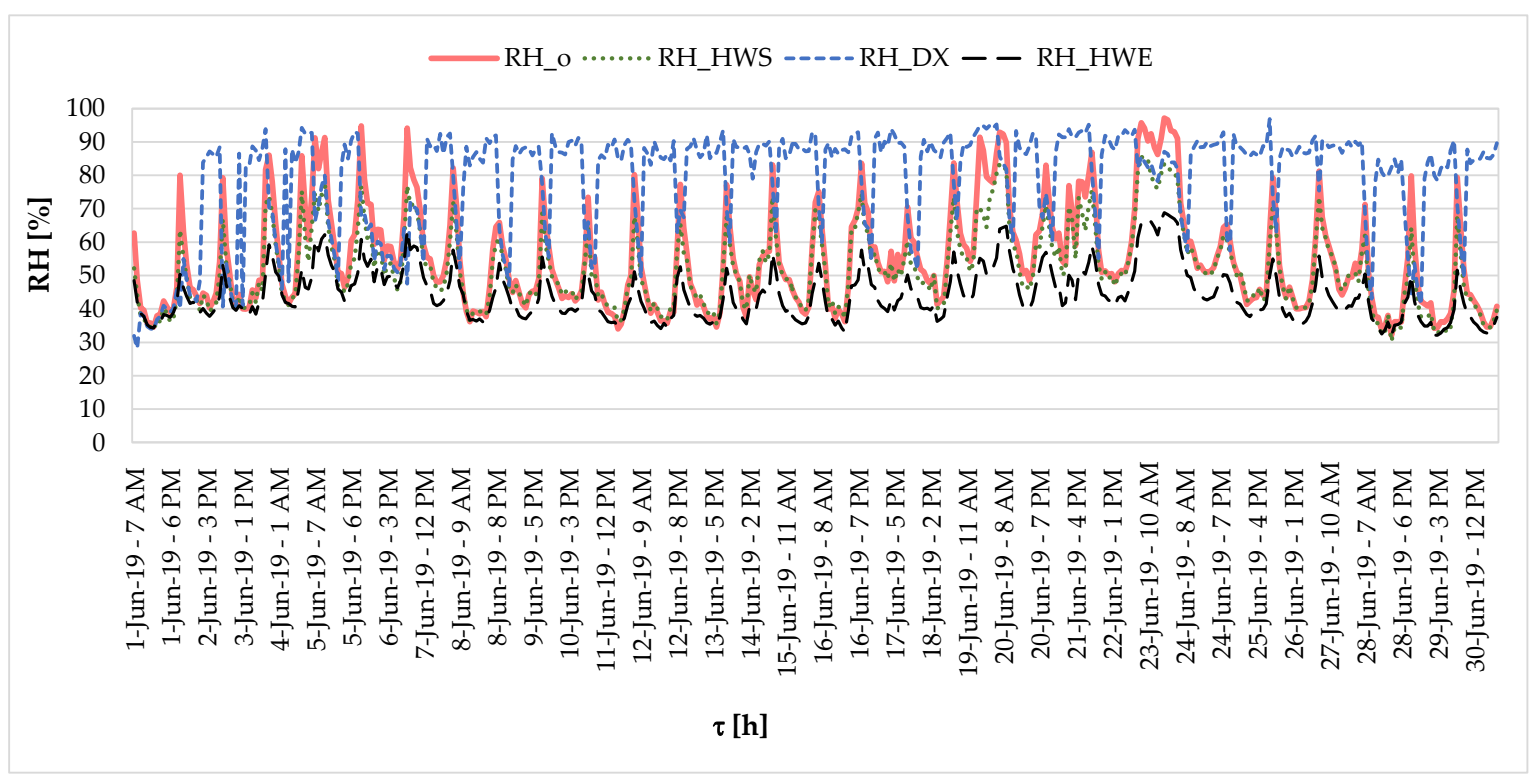

Figure 6. The air relative humidity values in the air handling processes.

The ambient air relative humidity decreased by about $60 \%$ due to the air cooling process. In this way, the supplied air relative humidity was around $90 \%$.

Figure 7 shows the enthalpy of the outdoor air $\left(h_{o}\right)$, the air in the supply outlet sections of the heat wheel ( $\left.h_{H W S}\right)$ and DX coil $\left(h_{D X}\right)$, and the exhaust inlet section of the heat wheel $\left(h_{H W E}\right)$ over time at hourly intervals in June.

Considering the hottest periods in the cooling season, the ambient air enthalpy decreased by about $8-10 \mathrm{~kJ} / \mathrm{kg}$ due to the pre-cooling effect of the heat wheel, and by an additional $30-35 \mathrm{~kJ} / \mathrm{kg}$, provided by air cooling of the DX coil. 


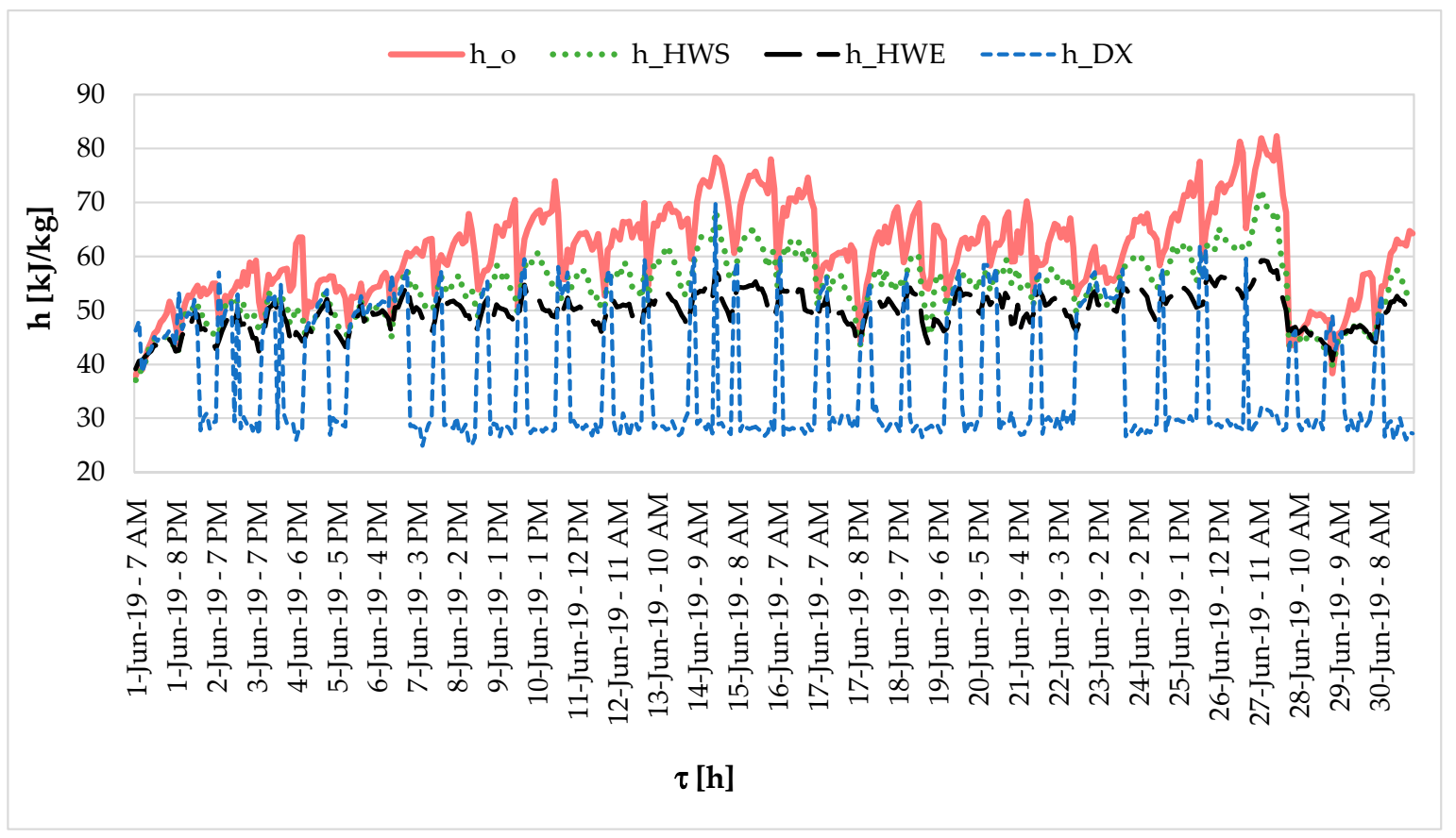

Figure 7. The air enthalpy values in the air handling processes.

Figure 8 shows the sensible effectiveness data $\left(\varepsilon_{\mathrm{s}}\right)$ for the outdoor air temperature in June.

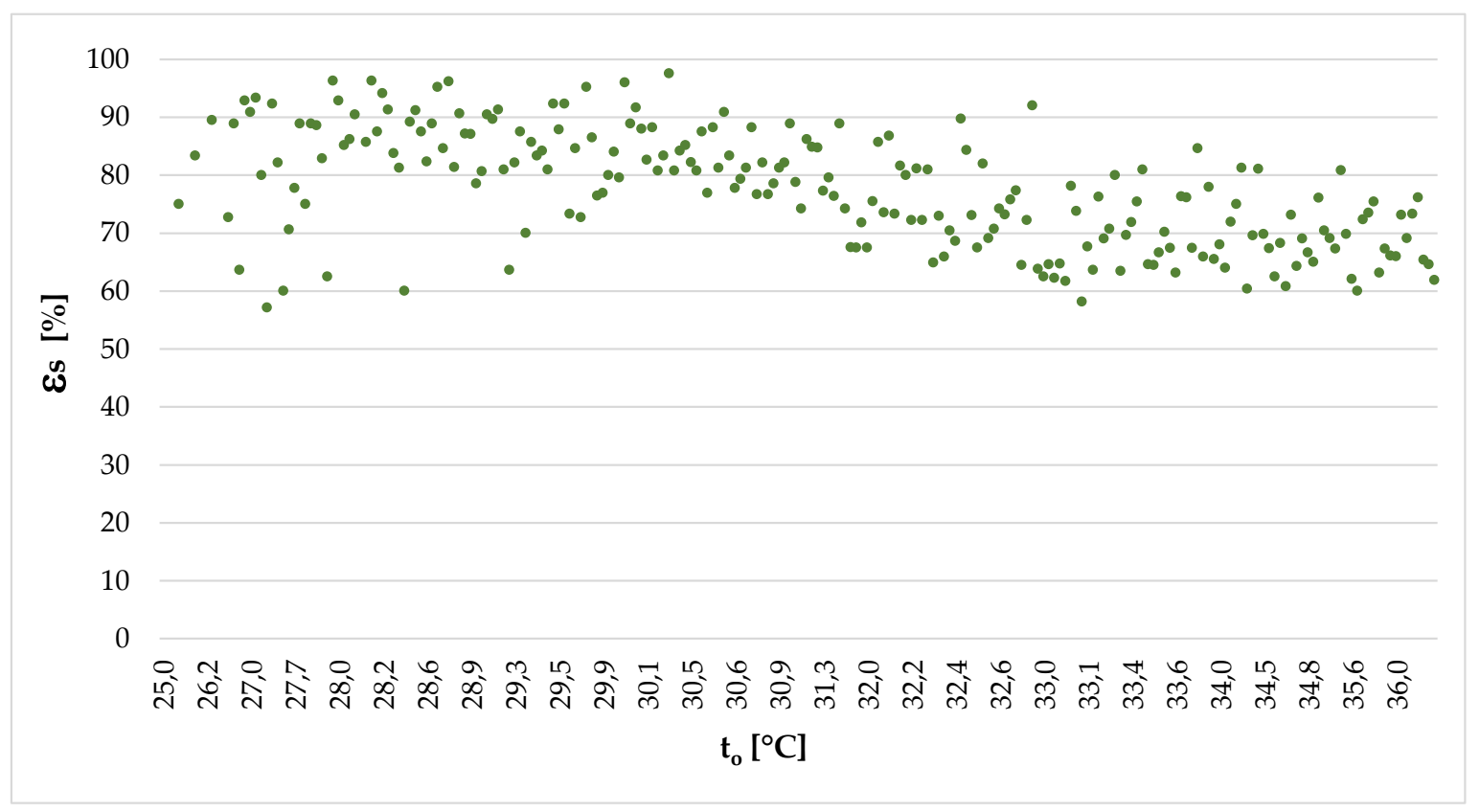

Figure 8. The sensible effectiveness values as a function of outdoor air temperature in June.

Based on the results, the average sensible effectiveness of the heat wheel was $79.6 \%$ during the whole cooling season and the maximum value of $97.6 \%$ was recorded in June.

Figure 9 shows the energy saving of the air-to-air rotary heat wheel $\left(\mathrm{Q}_{\mathrm{HW} \_ \text {saved }}\right)$ in terms of the energy consumption of the DX coil, and the cooling energy consumption of the DX coil with the heat wheel operation ( $\left.\mathrm{Q}_{\mathrm{DX} \_\mathrm{HW}}\right)$ and without the heat wheel operation $\left(\mathrm{Q}_{\mathrm{DX}} \mathrm{WO}_{-} \mathrm{HW}\right)$, when the DX coil directly cools the hot ambient outdoor air to the supply air conditions during the cooling season. 


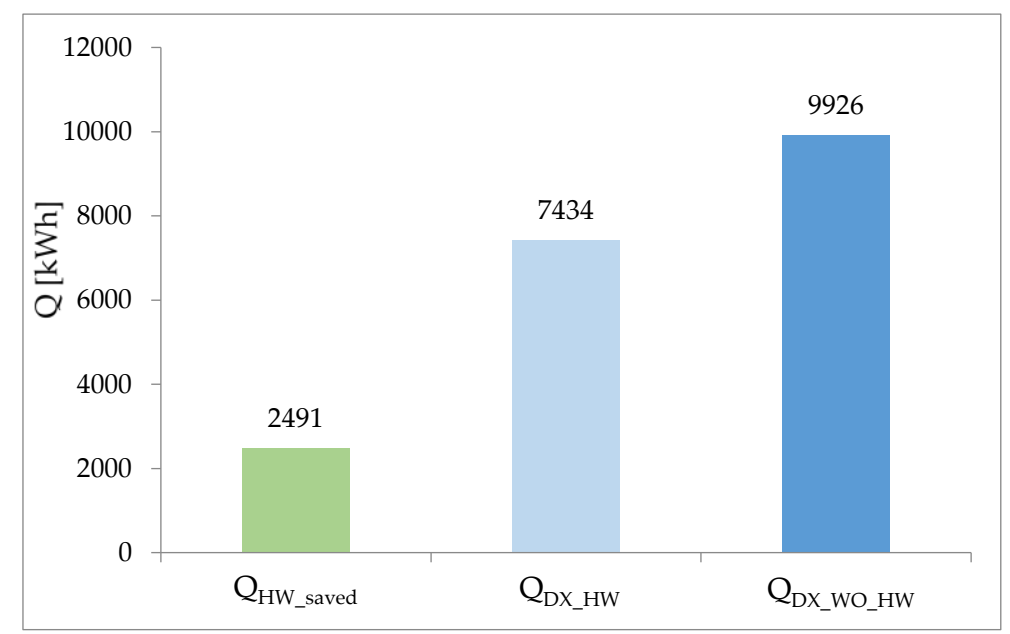

Figure 9. The energy recovery and auxiliary cooling energy consumption for ventilation.

Based on the results, the energy saving of the heat wheel was $2491 \mathrm{kWh}$ in terms of the energy consumption of the DX coil, the cooling energy consumption of the DX coil with the heat wheel operation was $7434 \mathrm{kWh}$, and that without the heat wheel operation was $9926 \mathrm{kWh}$.

Figure 10 shows the electric energy consumption of the outdoor unit based on the direct real electric energy consumption measurements ( $\mathrm{PVRV}_{\mathrm{VHW}} \mathrm{H}$ ) and the calculations made using the recorded air condition parameters with ( $\left.\mathrm{P}_{\mathrm{VRV} \_H W}\right)$ and without the heat wheel operation $\left(\mathrm{P}_{\mathrm{VRV}} \mathrm{WO}_{-} \mathrm{HW}\right)$ for the whole cooling period.

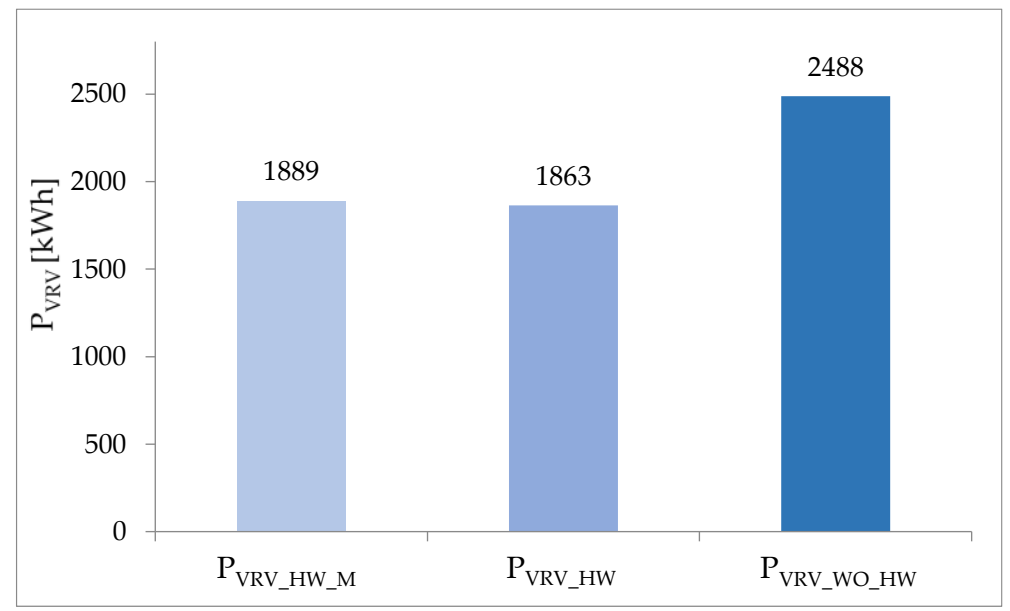

Figure 10. The electric energy consumption of the outdoor unit.

The real electric energy consumption of the outdoor unit based on the measurements was $1889 \mathrm{kWh}$ and the calculations resulted in $1863 \mathrm{kWh}$ consumption with and $2488 \mathrm{kWh}$ consumption without the heat wheel operation for the whole cooling period.

Since the difference $\left(\Delta \mathrm{P}_{\mathrm{VRV} \_\mathrm{HW}}\right)$ is only $26 \mathrm{kWh}$ and rate of deviation $\left(\Delta \mathrm{P}_{\mathrm{VRV} \_\mathrm{HW} \_\mathrm{REL}}\right)$ is $1.36 \%$ between the values of the measured and calculated electric energy consumption of the variable refrigerant volume (VRV) outdoor unit with the heat wheel operation, Figure 10 shows very good agreement between the experimental and numerical results. The evaluated energy efficiency ratio is 3.94 based on the measurements $\left(E E R_{M}\right)$ conducted for the whole investigated cooling season, which is only 0.05 less than the value of 3.99 given by the producer. The energy impact of the heat wheel results in $624 \mathrm{kWh}$ energy being saved ( $\left.\triangle \mathrm{P}_{\mathrm{VRV} \_H W_{-} \text {saved }}\right)$, which is equivalent to a $25.1 \%$ energy saving rate $\left(\triangle \mathrm{P}_{\mathrm{VRV} \_H W} \mathrm{H}_{\text {saved_REL }}\right)$ in terms of the electric energy consumption of the outdoor unit for the whole cooling period, compared to the system without the heat wheel operation. 
Figure 11 shows the measured $\mathrm{CO}_{2}$ concentration of the outdoor air $\left(\mathrm{C}_{\mathrm{CO} 2 \mathrm{o}}\right)$, the air in the supply outlet section of the heat wheel $\left(\mathrm{C}_{\mathrm{CO} 2 \_\mathrm{HWS}}\right)$, and the exhaust inlet section of the heat wheel $\left(\mathrm{C}_{\mathrm{CO} 2 \_\mathrm{HWE}}\right)$ over time at hourly intervals in June. There are a few hours in Figure 11 when the recorded $\mathrm{CO}_{2}$ values of the air were lower in the supply outlet section than in the exhaust inlet section of the heat wheel, probably due to the uncertainties and transient response characteristics of the $\mathrm{CO}_{2}$ sensors.

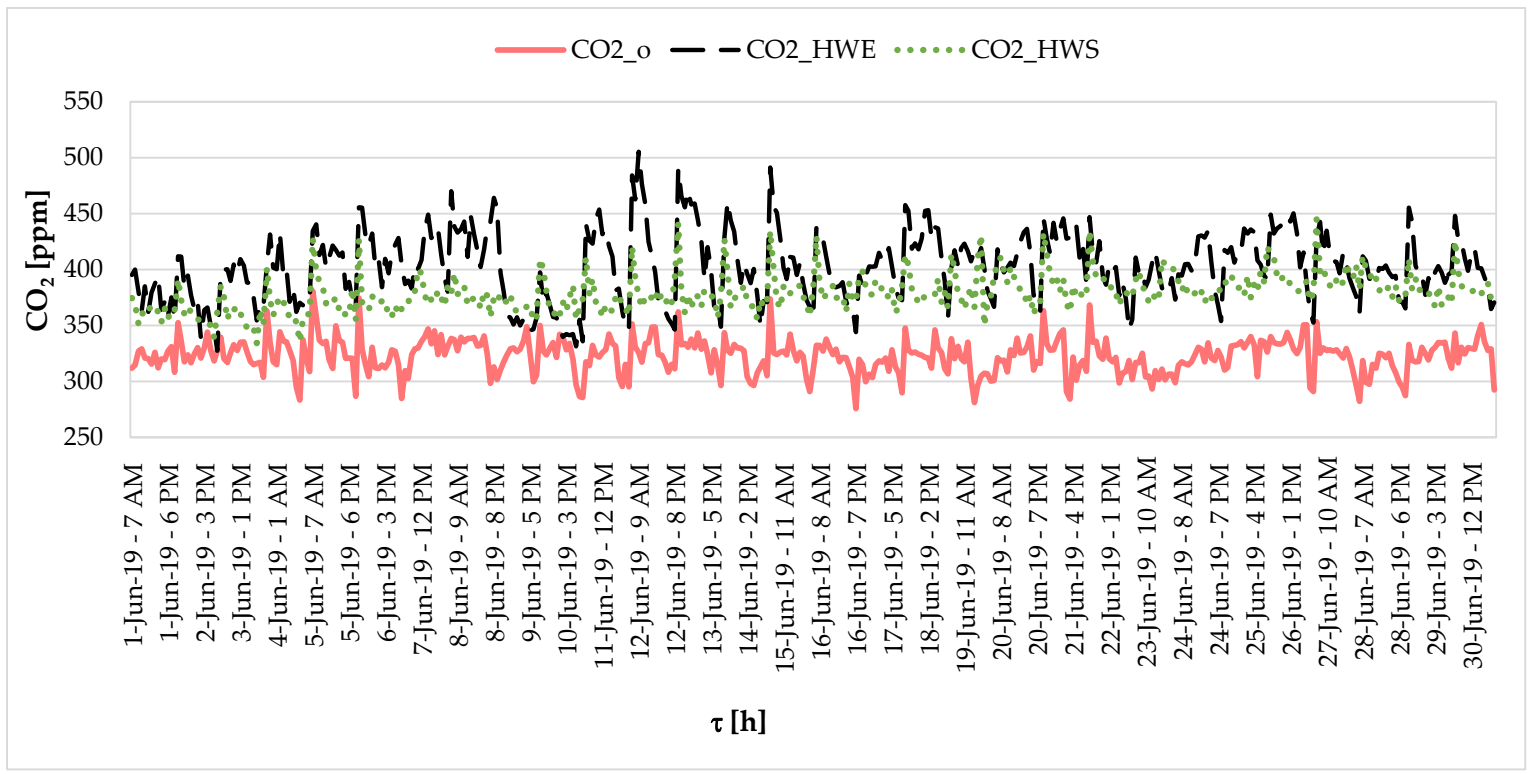

Figure 11. The carbon dioxide values in the investigated supply and exhaust sections of the heat wheel.

Having completed the measurements of the whole cooling period, the average $\mathrm{CO}_{2}$ cross-contamination value $\left(\overline{\Delta C}_{\mathrm{CO} 2 \text { cross_ } A V}\right)$ was $63.9 \mathrm{ppm}$. The average value of the $\mathrm{CO}_{2}$ concentration in the exhaust inlet section of the heat wheel $\left(\bar{C}_{C O 2}{ }_{2} H W E_{-} A V\right)$ was 390.1 ppm. Based on the results, the relative average of $\mathrm{CO}_{2}$ cross-contamination $\left(\overline{\Delta C}_{C O 2 \_R E L}\right)$ was $16.4 \%$ and the maximum value $\left(C_{C O 2 \_R E L \_M A X}\right)$ was recorded as $30.1 \%$, considering the whole cooling season. To determine how the obtained values influence the indoor air quality inside of the conditioned spaces, further indoor air quality measurements are necessary (with the use of further measurement devices and questionnaires), which can act as a continuation of this research work, but exceed the limitation of this recent ongoing research project.

\section{Conclusions}

In this research work, a field study was carried out on the cooling energy performance of an existing, operating ventilation system under the operation of an air-to-air rotary heat wheel and direct expansion cooling coil, connected to a variable refrigerant volume outdoor unit. The major findings obtained from the study can be summarized as follows:

1. The operation of the heat wheel has a significant cooling energy saving impact on the electric energy consumption of the outdoor unit. Comparing the measured ventilation system with an air handling unit without a heat wheel operation, the cooling energy consumption is $25.1 \%$ higher;

2. Based on the measurements, the real sensible effectiveness and the $\mathrm{CO}_{2}$ cross-contamination of the heat wheel are not in accordance with the design assumptions for the cooling period;

3. The sensible effectiveness of the heat wheel performed $4.7 \%$ higher than the data $(74.9 \%)$ given in the technical data book of the producer;

4. Having completed the measurements for the whole cooling period, the amount of $\mathrm{CO}_{2}$ cross-contamination in the heat wheel was much higher (with $16.4 \%$ relative average and $30.1 \%$ maximum values) than predicted during the designing phase. 
Future work will focus on heating and annual energy performance investigations by conducting further field studies on the system. Moreover, simulation model development will also be considered for an annual energy consumption investigation of the existing ventilation system and model validation is planned based on data given by an annual field study. The long-term goal is to develop a simulation model which is suitable for determination of the energy consumption of ventilation systems in the design phase with a high accuracy.

Funding: The sensors, instruments, and transducers were financially supported and installed, and BMS software for data recording was made for this research work, by the national Intherm Ltd. In addition, the research project was financially supported by the National Research, Development and Innovation Office from the NRDI Fund [grant number: NKFIH PD_18 127907], the János Bolyai Research Scholarship of the Hungarian Academy of Sciences, Budapest, Hungary. Moreover, the research reported in this paper has been supported by the National Research, Development and Innovation Fund (TUDFO/51757/2019-ITM, Thematic Excellence Program), as well as the Higher Education Excellence Program of the Ministry of Human Capacities in the frame of Artificial Intelligence research area of Budapest University of Technology and Economics (BME FIKP-MI).

Acknowledgments: The author wishes to thank Árpád Nagy and Gyula Szabó from the group of Intherm Ltd., as well as Balázs Zuggó and Noémi Bálint from the group of Daikin Hungary Ltd., for providing their professional technical and practical knowledge for the research background of this research. Moreover, special thanks go to Laith Al-Hyari for his contribution in simple data saving.

Conflicts of Interest: The author declares no conflicts of interest.

\section{Nomenclature}

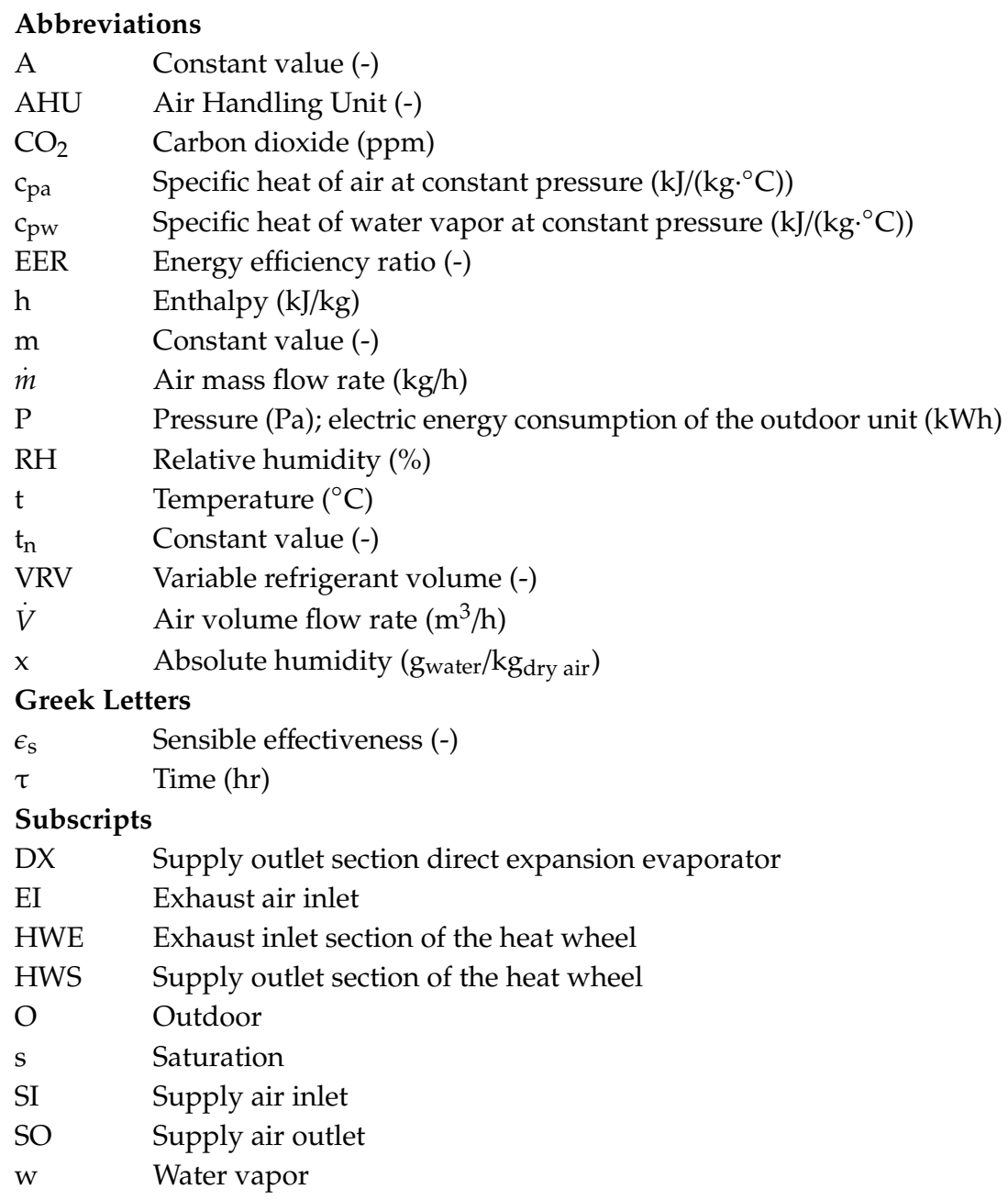




\section{References}

1. Zhong, C.; Yan, K.; Dai, Y.; Jin, N.; Lou, B. Energy Efficiency Solutions for Buildings: Automated Fault Diagnosis of Air Handling Units Using Generative Adversarial Networks. Energies 2019, 12, 527. [CrossRef]

2. Misevičiūtė, V.; Valančius, K.; Motuzienė, V.; Rynkun, G. Analysis of exergy demand for air heating of an air handling unit. Energy Effic. 2017, 10, 989-998.

3. Cui, X.; Mohan, B.; Islam, M.R.; Chua, K.J. Investigating the energy performance of an air treatment incorporated cooling system for hot and humid climate. Energy Build. 2017, 151, 217-227. [CrossRef]

4. Ukai, M.; Tanaka, H.; Tanaka, H.; Okumiya, M. Performance analysis and evaluation of desiccant air-handling unit under various operation condition through measurement and simulation in hot and humid climate. Energy Build. 2018, 172, 478-492. [CrossRef]

5. Shea, R.P.; Kissock, K.; Selvacanabady, A. Reducing university air handling unit energy usage through controls-based energy efficiency measures. Energy Build. 2019, 194, 105-112. [CrossRef]

6. Kusiak, A.; Zeng, Y.; Xu, G. Minimizing energy consumption of an air handling unit with a computational intelligence approach. Energy Build. 2013, 60, 355-363. [CrossRef]

7. Guo, Y.; Zhang, G.; Zhou, J.; Wu, J.; Shen, W. A techno-economic comparison of a direct expansion ground-source and a secondary loop ground-coupled heat pump system for cooling in a residential building. Appl. Therm. Eng. 2012, 35, 29-39. [CrossRef]

8. Jorissen, F.; Boydens, W.; Helsen, L. Validated air handling unit model using indirect evaporative cooling. J. Build. Perform. Simul. 2018, 11, 48-64. [CrossRef]

9. Wallin, J.; Claesson, J. Improving heat recovery using retrofitted heat pump in air handling unit with energy wheel. Appl. Therm. Eng. 2014, 62, 823-829. [CrossRef]

10. Yun, G.Y.; Choi, J.; Kim, J.T. Energy performance of direct expansion air handling unit in office buildings. Energy Build. 2014, 77, 425-431. [CrossRef]

11. Ukai, M.; Okumiya, M. Comparison of Behaviour and Energy Performance of Desiccant Air Handling Unit under Various Control Method. In IOP Conference Series: Earth and Environmental Science, Proceedings of the 4th Asia Conference of International Building Performance Simulation Association (ASIM2018), Hong Kong, China, 3-5 December 2018; IOP Publishing: Bristol, UK, 2019; Volume 238, p. 012027.

12. Angrisani, G.; Roselli, C.; Sasso, M.; Tariello, F. Dynamic performance assessment of a solar-assisted desiccant-based air handling unit in two Italian cities. Energy Convers. Manag. 2016, 113, 331-345. [CrossRef]

13. Kim, S.H.; Moon, H.J. Case study of an advanced integrated comfort control algorithm with cooling, ventilation, and humidification systems based on occupancy status. Build. Environ. 2018, 133, 246-264. [CrossRef]

14. Li, N.; Xia, L.; Shiming, D.; Xu, X.; Chan, M. Dynamic modeling and control of a direct expansion air conditioning system using artificial neural network. Appl. Energy 2012, 91, 290-300. [CrossRef]

15. Stamatescu, G.; Stamatescu, I.; Arghira, N.; Fagarasan, I. Data-Driven Modelling of Smart Building Ventilation Subsystem. J. Sens. 2019, 2019, 3572019. [CrossRef]

16. Hong, G.; Kim, B.S. Development of a Data-Driven Predictive Model of Supply Air Temperature in an Air-Handling Unit for Conserving Energy. Energies 2018, 11, 407. [CrossRef]

17. Noussan, M.; Carioni, G.; Degiorgis, L.; Jarre, M.; Tronville, P. Operational performance of an Air Handling Unit: Insights from a data analysis. Energy Procedia 2017, 134, 386-393. [CrossRef]

18. Bareschino, P.; Pepe, F.; Roselli, C.; Sasso, M.; Tariello, F. Desiccant-Based Air Handling Unit Alternatively Equipped with Three Hygroscopic Materials and Driven by Solar Energy. Energies 2019, 12, 1543. [CrossRef]

19. Daikin Ventilation Catalogue. Daikin Europe Naamloze Vennootschap, Zandvoordestraat 300, 8400 Oostende, Belgium, RPR Oostende. 2019. Available online: https://www.daikin.eu/content/dam/documentlibrary/catalogues/Ventilation\%20catalogue\%20-\%20ECPEN13-203_Catalogues_English.pdf (accessed on 8 August 2019).

20. Oyj, V. Vaisala, Humidity Conversion Formulas. Helsinki, Finland. 2013. Available online: https: //www.hatchability.com/Vaisala.pdf (accessed on 8 November 2019).

21. Rajput, R.K. Thermal Engineering, 6th ed.; Firewall/Laxmi Publications Ltd.: New Delhi, India, 2006; ISBN 81-7008-834-8. 
22. European Committee for Standardization. Ventilation for Buildings_Performance Testing of Components/Products for Residential Ventilation-Part 7: Performance Testing of Components/Products of Mechanical Supply and Exhaust Ventilation Units (Including Heat Recovery) for Mechanical Ventilation Systems Intended for Single Family Dwellings; EN 13141-7:2010; CEN: Brussels, Belgium, 2010.

23. American Society of Heating. Method of Testing Air-To-Air Heat Exchangers, ASHRAE Standard 84-1991; American Society of Heating, Refrigerating and Air Conditioning Engineers Inc.: Atlanta, GA, USA, 1991.

(C) 2019 by the author. Licensee MDPI, Basel, Switzerland. This article is an open access article distributed under the terms and conditions of the Creative Commons Attribution (CC BY) license (http://creativecommons.org/licenses/by/4.0/). 